\title{
Postexertional Airway Rewarming and Thermally Induced Asthma New Insights into Pathophysiology and Possible Pathogenesis
}

\author{
E. R. McFadden, Jr., Kimberly Ann M. Lenner, and Kingman P. Strohl \\ Asthma and Allergic Disease Center and Departments of Medicine of University Hospitals and Case Western Reserve University School of \\ Medicine, Cleveland, Ohio 44106
}

\begin{abstract}
To determine if postexercise thermal events play a role in exercise-induced asthma (EIA), nine normal and eight asthmatic subjects on three occasions exercised while they inhaled frigid air. During the recovery period, either cold air, air at room temperature and humidity, or air at body conditions was administered in a random fashion. On a fourth occasion, body-condition air was given during exercise. Pulmonary mechanics were measured before and after each challenge. No changes in mechanics developed when air at body conditions was inhaled during exercise, however, increasing the heat content of the air during recovery produced progressively greater obstruction in both groups. On a separate occasion, seven asthmatics hyperventilated frigid air and either recovered spontaneously or had their ventilation slowly reduced. Controlling ventilation markedly attenuated the obstructive response. These data demonstrate that the severity of EIA is dependent not only on airway cooling but also upon the rapidity and magnitude of airway rewarming postchallenge.
\end{abstract}

\section{Introduction}

It is now appreciated that reductions in airstream and tracheal wall temperatures are normal occurrences during periods of hyperpnea, and it is well established that when these intrapulmonary thermal changes become sufficiently severe, bronchial obstruction develops in asthmatic as well as in normal individuals (1-7). The mechanism by which airflow limitation develops is unknown, however, and although several theories have been proposed, none of them accounts for all of the observations in the literature (8-10).

One area that has not been previously evaluated is the possibility that the thermal events that take place in the immediate posthyperpnea period contribute to the phenomenon. It is well documented clinically and physiologically that airway obstruction typically develops after exercise or hyperventilation ceases $(4-6,11)$, and since recent data suggest that there are large fluctuations in intrathoracic temperatures during this period (1-3), we wondered if they could be playing a role.

We tested this idea with two sets of experiments. In the first, we varied the temperature and humidity of the air inspired during the recovery period, and in the second, we controlled the rate

Address reprint requests to Dr. E. R. McFadden, Jr., Asthma and Allergic Disease Center, University Hospitals, 2074 Abington Road, Cleveland, OH 44106. 1986.

Received for publication 10 May 1985 and in revised form 11 February

\section{J. Clin. Invest.}

(C) The American Society for Clinical Investigation, Inc.

0021-9738/86/07/0018/08 \$1.00

Volume 78, July 1986, 18-25 at which the postchallenge ventilation decreased. Our observations form the basis of this report.

\section{Methods}

In the section dealing with altering the heat content of the air postexercise, data were collected from nine normal subjects (four males and five females) with a mean age of $28 \pm 2$ (SEM) yr and eight asymptomatic asthmatics (five males and three females) aged $26 \pm 6$ yr. None of the asthmatics had been taking cromolyn sodium or glucocorticoids in the $6 \mathrm{wk}$ preceding the study, and none were taking sustained release bronchodilator preparations. All refrained from using any medication for $24 \mathrm{~h}$ prior to any study day. Only one normal subject was a cigarette smoker. All of the other participants were nonsmokers.

After giving informed consent, each subject underwent three bronchoprovocations consisting of $4 \mathrm{~min}$ of exhausting leg work on a cycle ergometer while breathing frigid air through a heat exchanger $(5,7,12)$. The water content of the air in the exchanger was $<1 \mathrm{mg} /$ liter, which for the purposes of this study was considered to be zero. During exercise the expired air was directed through a calibrated dry gas meter so that minute ventilation $\left(\dot{\mathrm{V}}_{\mathrm{E}}\right)^{1}$ could be measured at 60 -s intervals. The work loads and inspired temperatures during the challenge were held constant for each trial.

Upon completion of the work load, the subjects either continued to breathe cold air for $5 \mathrm{~min}$ of the recovery period or were switched immediately, for an equal time period, to air at ambient room temperature and humidity or to fully saturated air at body temperature. By the end of $5 \mathrm{~min}$, all subjects breathed room air.

Each study was performed on a separate day and the order in which the recovery gases were given was randomly determined. Prior to exercise, at the end of the 5-min recovery period, and at each 5-min interval thereafter for $25 \mathrm{~min}$, the subjects performed maximal forced exhalations in triplicate with a waterless spirometer. Their best effort, as defined by the curve with the largest forced expiratory volume in one second $\left(\mathrm{FEV}_{1}\right)$ was chosen for analysis.

The body condition air was generated with a second heat exchanger in series with a bubble humidifier (4-6). The temperatures of the inspired air $\left(T_{i}\right)$, thermal baths, and bubble humidifier were continuously recorded during exercise and recovery. In the room air experiments, relative humidity was measured hygroscopically. Inspired water content was calculated from standard tables (13). Validation of this approach has been extensively documented in previous studies using volumetric techniques (4-7).

On one other occasion, the subjects were exercised a fourth time at the same cycle setting as previously, but in this instance air at body conditions of temperature and humidity was inhaled during the performance of the work. Recovery took place with the breathing of room air.

We knew from previous studies that the temperature and humidity of the air inspired during exercise did not influence $\dot{V}_{E}$ or respiratory frequencies (4-6). To determine if these factors were also without effect upon the ventilatory pattern after exercise, we performed a preliminary

1. Abbreviations used in this paper: B, baseline; EIA, exercise-induced asthma; $\mathrm{FEV}_{1}$, forced expiratory volume in $1 \mathrm{~s}$; Rec, recovery; $T_{\mathrm{i}}$, temperature of inspired air; $\dot{V}_{E}, 1$ min ventilation of expired air; $W C_{i}$, water content of inspired air. 
study in which 25 subjects ( 15 normal and 10 asthmatic) exercised on a cycle ergometer on three occasions while breathing frigid air. At the end of each exercise period, they were given one of the three test gases to inhale for $5 \mathrm{~min}$, while $\dot{V}_{E}$ was serially recorded.

In the second phase of our investigations into the effects of rewarming the airways, we wished to determine if controlling the rate at which $\dot{V}_{E}$ decreases in the immediate postprovocational period would alter the subsequent obstructive response. Seven asthmatics with heightened responsiveness to cold air, as determined from a preliminary study, served as our subjects. There were six females and one male with a mean age of $28 \pm 2$ years. Three of the subjects participated in the first part above and four were new recruits. The new subjects were also nonsmokers and they too refrained from the use of cromolyn, steroids, and bronchodilators prior to participation.

Each individual performed 4 min of isocapnic hyperventilation on two occasions while inhaling frigid air through the heat exchanger using previously reported techniques $(6,7,14)$. As in former studies, expired air was directed away from the heat exchanger into a reservoir balloon that was being constantly evacuated at a known rate through a calibrated rotameter. The subjects were coached to respire so as to keep the balloon filled, and in so doing, their $\dot{\mathrm{V}}_{\mathrm{E}}$ could be set to any desired value. Endtidal carbon dioxide concentration was monitored with a Beckman LB2 analyzer (Beckman Instruments, Inc., Fullerton, CA), and sufficient carbon dioxide was added to the inspiratory port of the exchanger to maintain end-tidal carbon dioxide at eucapnic levels. The temperature of the heat exchanger was similar to that used in the first set of studies described above. Levels of $\dot{V}_{E}$ were chosen for study that were known to reduce $F E V_{1} 20-25 \%$. Minute ventilation and $T_{\mathrm{i}}$ were kept constant for each subject for each trial. Upon completion of the challenges, the subjects either simply stopped hyperventilating and breathed room air in the usual fashion, or they remained on the heat exchanger while their $\dot{\mathrm{V}}_{\mathrm{E}}$ was reduced in 10-liter increments at 4-min intervals to resting levels. These two trials were designated "spontaneous" and "controlled" recovery, respectively. On a third occasion, each subject inhaled cold air during quiet tidal breathing. Pulmonary mechanics were measured before and serially after each challenge. In the controlled $\dot{V}_{E}$ study, they were also measured at each change in $\dot{V}_{E}$ by having the subjects take a maximum inhalation from the heat exchanger and exhale through a valve into the spirometer. Their next breath was once more on the heat exchanger.

The data were analyzed by paired $t$ tests and one and two factor analyses of variance.

\section{Results}

The mean work loads for the normal and asthmatic subjects were $800 \pm 70$ and $881 \pm 147$ kilopond meters (KPM), respectively. The individual data for $\dot{V}_{E}$, inspired air conditions and changes in pulmonary mechanics associated with each trial for the normal subjects are listed in Table I. For ease of presentation of the

Table I. Individual Data in Normal Subjects

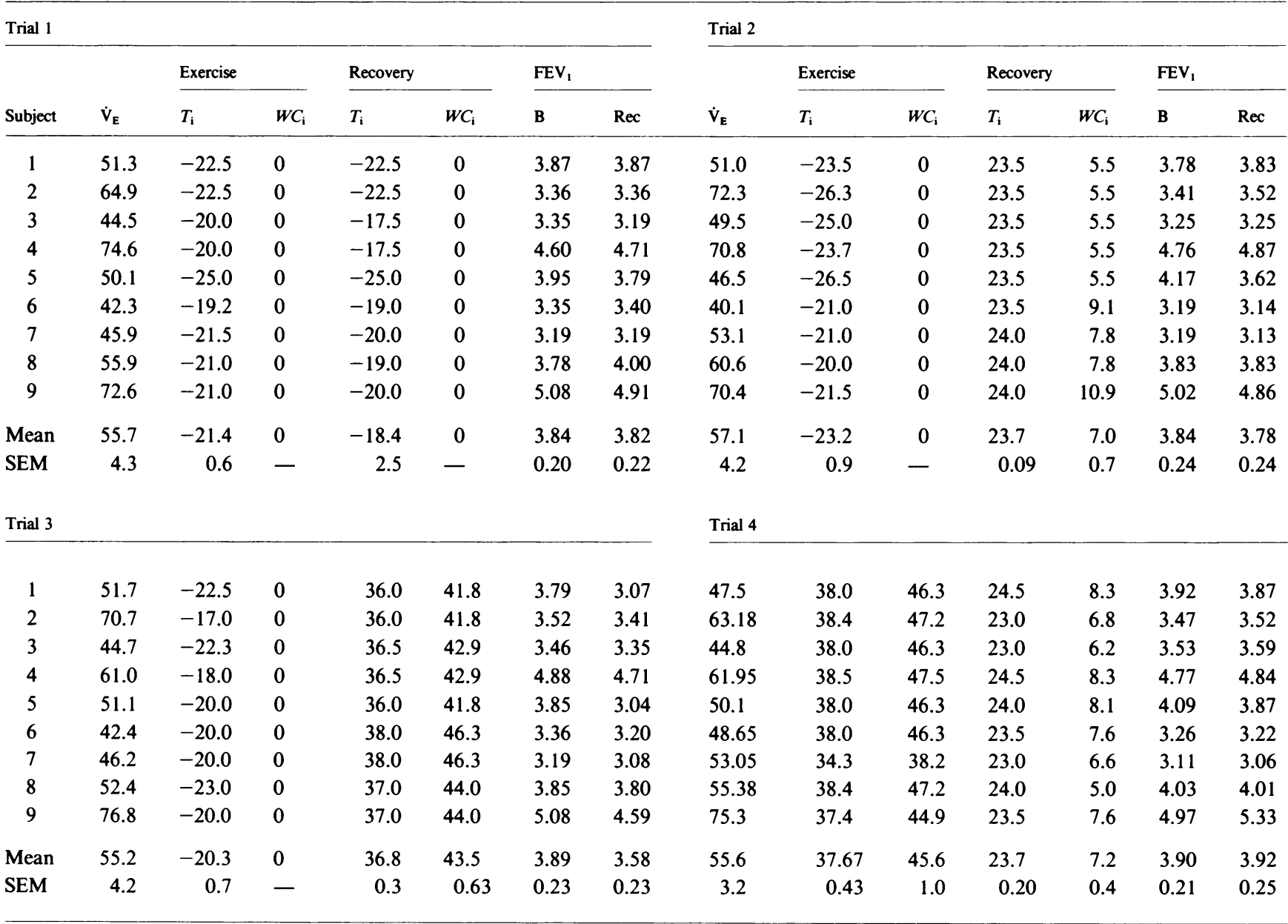

Individual data in normal subjects. $\dot{\mathrm{V}}_{\mathrm{E}}=$ minute ventilation in liters per minute; $T_{\mathrm{i}}=$ temperature of the inspired air in ${ }^{\circ} \mathrm{C} ; W C_{\mathrm{i}}=$ water content of the inspired air in milligrams $\mathrm{H}_{2} \mathrm{O}$ per liter air; $\mathrm{FEV}_{1}=$ forced expiratory volume in $1 \mathrm{~s}$ in liters; $\mathrm{B}=$ before exercise; Rec = after 5 min of inhaling the test gas in the recovery period. 
data, the cold, room, and body condition air recovery experiments were designated trials 1,2 , and 3 , respectively. The experiment in which body condition air was inhaled during exercise was designated trial 4 . In the normal individuals, in the three exercise trials using subfreezing air, the average $\dot{V}_{E}$ ranged between 55.2 and 57.1 liters/min, while $T_{\mathrm{i}}$ varied between -20 and $-23^{\circ} \mathrm{C}$. There were no significant differences among trials for either variable demonstrating uniform application of the thermal components of the exercise stimulus. In the experiments in which cold, room, and body condition air was given for the first $5 \mathrm{~min}$ of the recovery periods, the mean values for $T_{\mathrm{i}}$ and water content of inspired air $\left(W C_{\mathrm{i}}\right)$ were: $-18.4^{\circ} \mathrm{C}$ with $0 \mathrm{mg}$ $\mathrm{H}_{2} \mathrm{O} ; 23.7^{\circ} \mathrm{C}$ with $7 \mathrm{mg} \mathrm{H}_{2} \mathrm{O}$; and $36.8^{\circ} \mathrm{C}$ with $43.5 \mathrm{mg} \mathrm{H}_{2} \mathrm{O}$, respectively. In the study in which body condition air was given during exercise (trial 4), the $\dot{\mathrm{V}}_{\mathrm{E}}$ matched that of previous challenges and the temperature and water content of the air were within $0.9 \pm 0.7^{\circ} \mathrm{C}$ and $2.0 \pm 1.5 \mathrm{mg} \mathrm{H}_{2} \mathrm{O} /$ liter, respectively, of that administered during recovery in trial $3(P=\mathrm{NS})$.

As shown in Table I, there were no significant differences among the baseline values for $\mathrm{FEV}_{1}$ for any trial. Exercise breathing frigid air was not followed by any significant changes in lung function when the subjects inhaled either subfreezing air or air at ambient room temperature and humidity for the first $5 \mathrm{~min}$ of the postexercise period. However, when the inhalation of warm moist air followed the completion of the work load, the subjects developed bronchial obstruction at the end of $5 \mathrm{~min}$, even though this gas had no effect when inspired during exercise $\left[\Delta \mathrm{FEV}_{1}\right.$ baseline $(\mathrm{B})$ to the 5 -min recovery point $(\mathrm{Rec})$ trial $3=-0.3$ liters, $P<0.02 ; \Delta \mathrm{FEV}_{1}$ trial $4=+0.02$ liters, $P$ = NS].

The overall pattern of response is shown in Fig. 1. With cold, room temperature, and body condition air the percent $\Delta \mathrm{FEV}_{1}$ $5 \mathrm{~min}$ after exercise increased from $-0.3 \pm 1.2$ to $-1.5 \pm 1.7$ and then to $-7.7 \pm 2.5 \%$, respectively $(\mathrm{F}=5.74 ; \mathrm{df}=2.24 ; P<0.01)$. The response following body condition air was significantly greater than that occurring with either of the other two conditions. When air at body conditions was inspired during exercise, $\mathrm{FEV}_{1}$ rose $+0.2 \pm 1.1 \%$ over baseline values.

The results of experiments in the asthmatics are contained in Table II and Fig. 2. Similar patterns to those in the normals

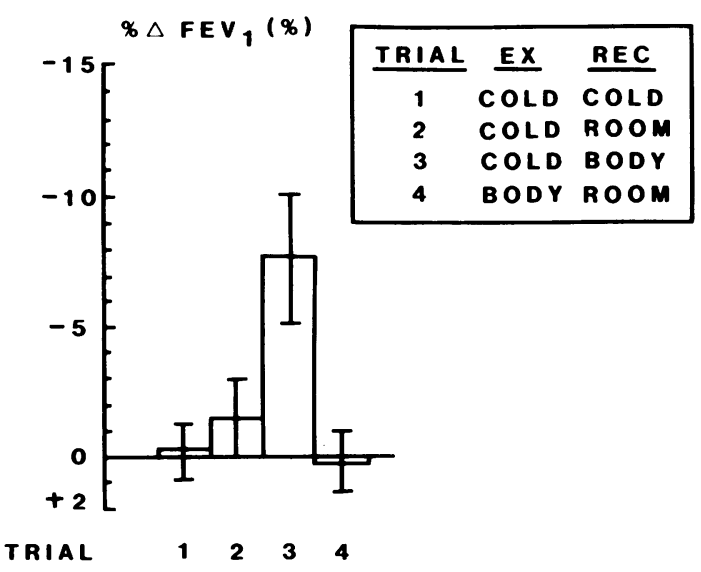

Figure 1. Pattern of response in pulmonary mechanics in normal subjects. The heights of the bars are mean values and the brackets represent 1 SEM. Percent $\Delta \mathrm{FEV}_{1}=$ percentage change in $1 \mathrm{~s}$ forced expiratory volume. for $\dot{\mathrm{V}}_{\mathrm{E}}, T_{\mathrm{i}}$, and $W C_{\mathrm{i}}$ were observed. Ventilation ranged between 61 and 67 liters/min and there were no significant differences among any of the four trials. There were no differences in $T_{\mathrm{i}}$ among trials 1 through 3 . The temperatures and water contents of the air inspired during the first $5 \mathrm{~min}$ of the recovery period were statistically identical to those used for the normal individuals. There were no differences in heat content between the moist warm air inhaled during recovery in trial 3 and during exercise in trial 4.

As with the normal participants, there were no significant differences among the preexercise $\mathrm{FEV}_{1}$ values for any trial. Unlike the normal subjects, however, each of the three trials in which cold air was given during exercise produced significant alterations in lung function. (Trial $1 \Delta \mathrm{FEV}_{1}$ baseline to the 5min recovery point $=0.51$ liter; $P<0.01 ;$ trial $2 \Delta \mathrm{FEV}_{1}=0.62$ liter; $P<0.005$; trial $3 \Delta \mathrm{FEV}_{1}=-1.05$ liters; $P<0.001$.) No change in mechanics occurred, however, when air at body conditions (trial 4$)$ was inspired during cycle ergometry $\left(\Delta \mathrm{FEV}_{1}\right.$ $=0.05$ liter; $P=\mathrm{NS}$ ). The pattern of change with each gas was similar to that observed in the normals (Fig. 2) (cold air percent $\Delta \mathrm{FEV}_{1}=-16.7 \pm 5.4$; room air $=-20.4 \pm 6.0$; body conditions $=-30.5 \pm 5.9 \%$ ). Seven of eight asthmatics had a larger change with room air than with cold air recovery, but the difference did not reach statistical significance by paired analysis. The size of the response with recovery on body condition air, however, was significantly greater than that in both the cold and room air recovery trials (mean difference in percent $\triangle \mathrm{FEV}_{1}$ cold vs. body $=13.7 \% ; P<0.02$; room vs. body $=10 \% ; P<0.05$ ).

The changes in the observed response with time in the asthmatics were shown in Figs. 3 and 4 . In trial 1, there was a lag in the development of the maximum response. $15 \mathrm{~min}$ after completing exercise, and $10 \mathrm{~min}$ after switching from cold to room temperature air, the $\mathrm{FEV}_{1}$ had fallen $21 \%$ from control (Figs. 3 and 4). This value was significantly greater by paired comparisons than that recorded at the end of the 5-min recovery period in this experiment $(P<0.05)$ and equaled that seen at the height of the response in trial 2 where only room air was inhaled (Fig. 4). The maximum response in trial 1, however, remained significantly less than that in trial 3 . By the 25 th min of the protocol, the obstruction began to remit.

In the other two experiments (trials 2 and 3), the maximum response was seen at the measurements made at 5 min postexercise (Fig. 3). In these studies postexercise recovery had begun by $15 \mathrm{~min}$. The degree of recovery was less, however, in the body condition experiment. By 15 min postexercise in trial 2, the $\mathrm{FEV}_{1}$ was $16 \%$ less than control (percent $\triangle \mathrm{FEV}_{1} 5$ min vs. 15 min, paired comparison, $P=0.06$ ), whereas it was still $22 \%$ in trial 3 at the same time (percent $\Delta \mathrm{FEV}_{1} 5$ vs. $15 \mathrm{~min} ; P=\mathrm{NS}$ ) (Fig. 4). (Fig. 5).

None of the test gases had any effect on postexercise $\dot{V}_{E}$

The data from the investigations examining the effects of controlling $\dot{\mathrm{V}}_{\mathrm{E}}$ in the recovery period are presented in Table III and Fig. 6 . In the two hyperventilation experiments, $\dot{V}_{E}$ ranged between 20 and 40 liters/min and was held constant between trials. In the experiment in which cold air was administered during quiet breathing, $\dot{\mathrm{V}}_{\mathrm{E}}$ averaged $12.5 \pm 1.5 \mathrm{liters} / \mathrm{min}$. The mean temperature of the inspired air ranged between -20.7 and $-21.7^{\circ} \mathrm{C}$ and there were no significant differences among trials.

As in the previous experiments, there were no significant differences among the preexercise $\mathrm{FEV}_{1}$ values for any study. 
Table II: Individual Data in Asthmatic Subjects

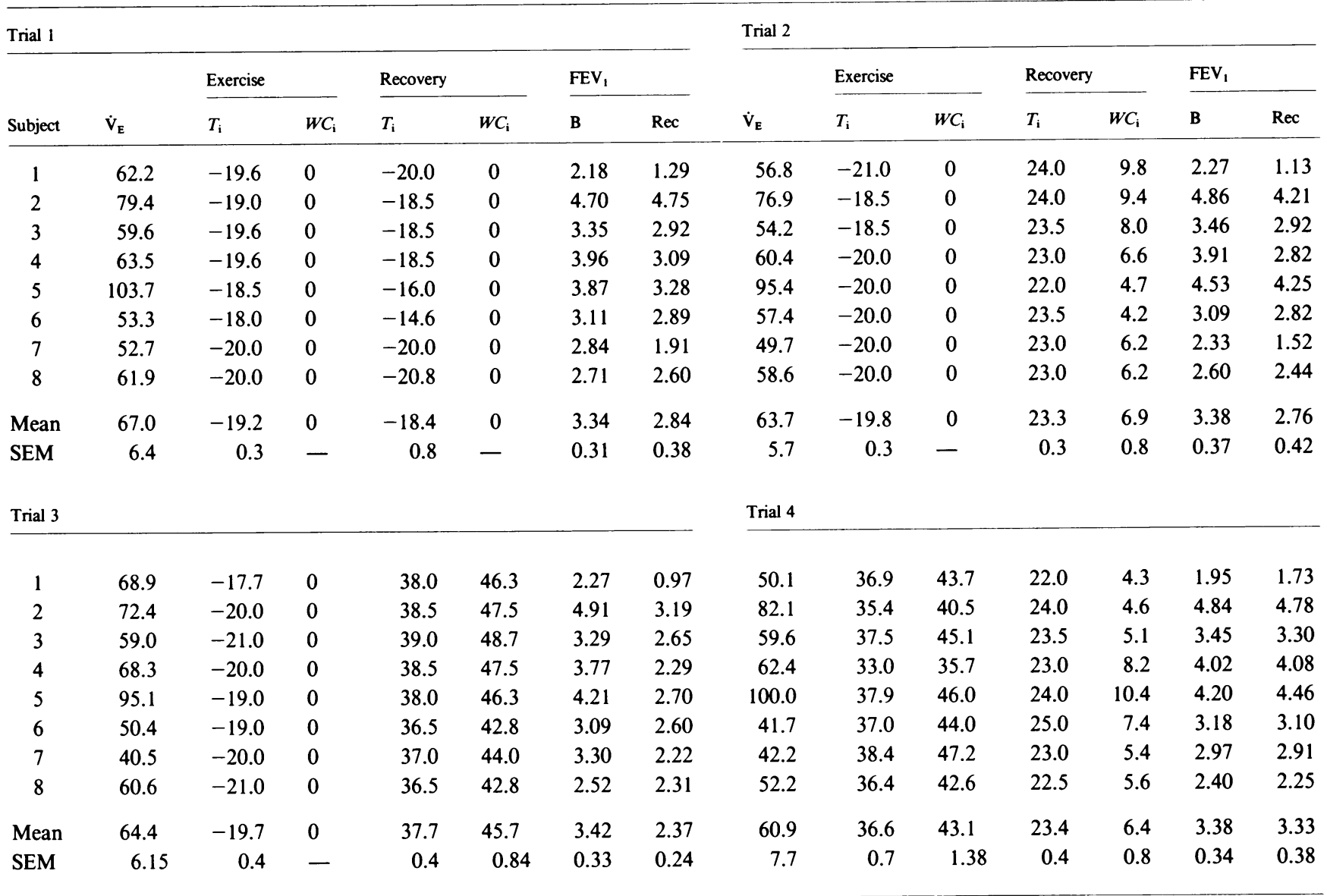

Individual data in asthmatic subjects. $T_{\mathrm{i}}=$ temperature of the inspired air in ${ }^{\circ} \mathrm{C} ; W C_{\mathrm{i}}=$ water content of the inspired air in milligrams of $\mathrm{H}_{2} \mathrm{O}$ per liter air; $\mathrm{FEV}_{1}=$ forced expiratory volume in $1 \mathrm{~s}$ in liters; $\mathrm{B}=$ before exercise; $\mathrm{Rec}=$ after 5 min of inhaling the test gas in the recovery period.

When the subjects decreased $\dot{V}_{E}$ rapidly following the first bronchoprovocation, $\mathrm{FEV}_{1}$ fell as expected with the decrease averaging $24.3 \pm 2.8 \%$ from control (Fig. 6). In contrast, when the same challenge was followed by a controlled reduction in $\dot{\mathrm{V}}_{\mathrm{E}}$,

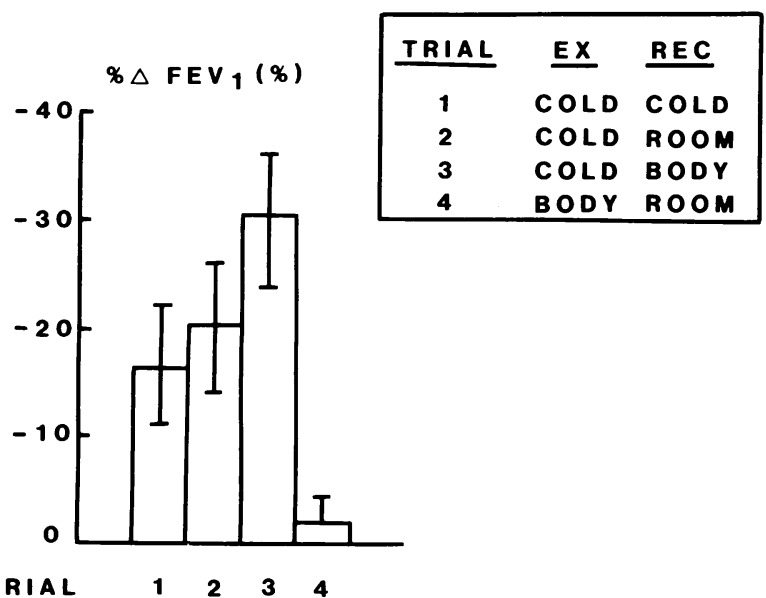

Figure 2. Pattern of response in pulmonary mechanics in asthmatic subjects. The format is identical to Fig. 1. the magnitude of the subsequent obstruction was significantly attenuated. In this circumstance, $F_{E V}$ still decreased significantly $(9.0 \pm 1.4 \%)$. However, the size of the response was approximately one-third of that in the spontaneous recovery experiment and was only slightly, but significantly larger than that observed when cold air was inhaled at rest $(-2.5 \pm 2.0 \%)$ (Fig. 6).

The time course of the responses in the two hyperventilation experiments is shown in Fig. 7. In the spontaneous recovery experiment mild airway obstruction was apparent immediately at the end of the period of hyperventilation (percent $\Delta \mathrm{FEV}_{1}$ $=-7.0 \pm 2.8 \%$ ). The maximum response developed over the next $5 \mathrm{~min}$ and thereafter, $\mathrm{FEV}_{1}$ began to return toward baseline. In the controlled recovery experiment the decrease in $\mathrm{FEV}_{1}$ at the end of the period of maximum hyperventilation was identical to that in the spontaneous recovery experiment. The subjects remained on the heat exchanger an average of $8.7 \pm 1.7 \mathrm{~min}$ longer than in the first trial and during this period $\mathrm{FEV}_{1}$ fell an additional small amount. However, the maximum response in this experiment was only a $9.8 \pm 2.4 \%$ change and it occurred immediately after the subjects came off the heat exchanger. At all time points, other than at $4 \mathrm{~min}$, the changes in $\mathrm{FEV}_{1}$ in this study were significantly less than those when $\dot{V}_{E}$ was not controlled. 



Figure 3. Time course of the response in asthmatics with each gas mixture. The data points are mean values and the brackets are 1 SEM. Ex $=$ exercise.

\section{Discussion}

The results of the present study demonstrate that the temperature and humidity of the inspired air, and the rate at which $\dot{V}_{E}$ changes after the performance of a thermal challenge are important interactive variables in determining the magnitude of the subsequent obstructive response. Therefore, it appears that the degree of bronchial narrowing that follows hyperpnea in individual

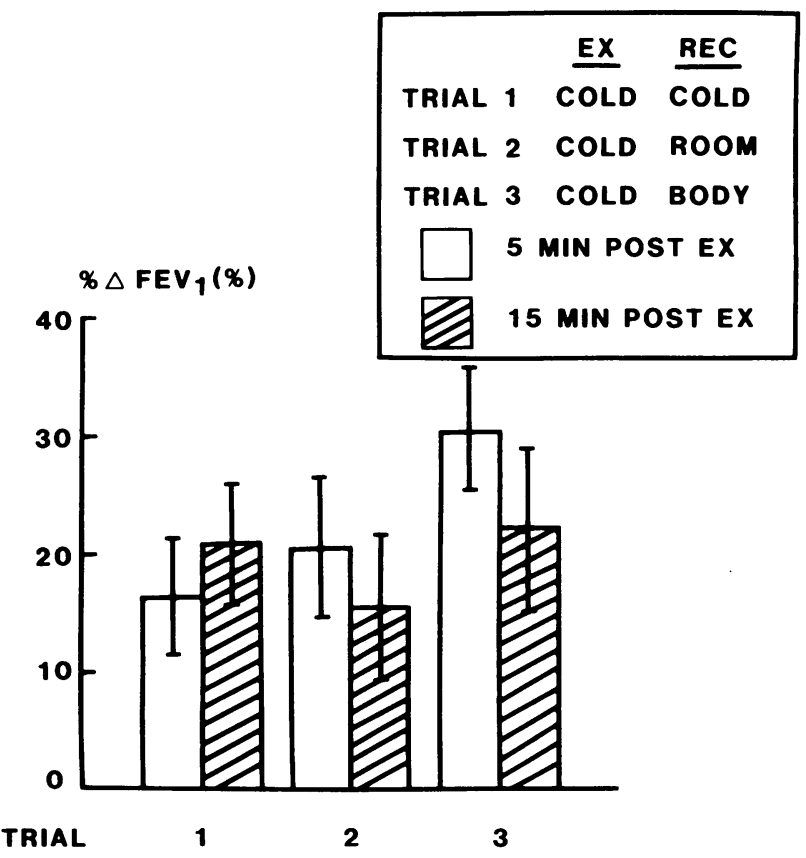

Figure 4. Comparison of the changes in pulmonary mechanics in the asthmatic subjects at 5 and $15 \mathrm{~min}$ postexercise. The heights of the bars are mean values and the brackets represent 1 SEM. subjects does not just depend upon the thermal events within the airways, or the degree of cooling that occurs during the performance of a challenge as has been formerly thought (4-6, 810 ), but also on the thermal environment present in the immédiate postprovocational period.

Our observations on the pulmonary mechanical consequences of altering the heat content of the air delivered after an exercise challenge are opposite to what occurs when those manipulations are undertaken during the challenge (4-6, 15-20). They, plus the pattern of recovery, and the effect of controlling $\dot{\mathrm{V}}_{\mathrm{E}}$ all support the concept that the magnitude and rate of airway rewarming play an important part in the pathophysiology of exercise-induced asthma (EIA). As a group, the results of the present study, coupled with those in the literature on respiratory heat transfer $(1-6,15-20)$, suggest that in order to induce obstruction, a thermal gradient seems to be necessary at the end of the challenge so that the cooling brought about by hyperpnea $(1-3,15)$ is followed by rewarming when the hyperpnea ceases. The rapid decreases in $\dot{V}_{E}$ that routinely follow exercise and hyperventilation bronchoprovocations (Fig. 5) easily set the stage for such a series of events to transpire. The higher the $\dot{\mathrm{V}}_{\mathrm{E}}$ and/ or the colder the air during exercise, or hyperventilation, the more airway temperature falls $(1-3,15)$. Hence, the greater the gradient at the end of the challenge the more abrupt the rewarming and the greater the obstructive response. Conversely, the less the level of $\dot{V}_{E}$ and/or the greater the heat content of the inspired gas during the challenge the less the temperature falls $(1-3,15)$. Consequently, the smaller the postchallenge gradient, the smaller the response. Application of exogenous heat to the airways, or otherwise increasing the heat content of the air, exaggerates the warming trend, whereas continuing to breathe cold air, or slowly decreasing $\dot{\mathrm{V}}_{\mathrm{E}}$, limits it. The consequences of the former are greater obstruction, while those of the latter are less obstruction.

The above sequence is nicely supported by the studies in the normal subjects, and the findings in the cold air trial in the asthmatics in the first set of experiments (Figs. 3 and 4). Unlike previous attempts in normal individuals where only subtle changes in sensitive tests of lung function could be induced even with very high levels of $\dot{V}_{E}(7,15)$, inhaling warm humid air at the end of a moderate challenge in the present study provoked a significant decrease in $\mathrm{FEV}_{1}$. In the cold air experiment, when the asthmatic subjects increased their airway temperatures by switching from cold to room air, their obstruction worsened and reached the same degree of severity as when they had inhaled room air in trial 2 (Figs. 3 and 4). At the same points in time, the obstruction with the other inspired air conditions was either stable or improving. It is of interest that a similar phenomenon was not observed in the hyperventilation experiment in which $\dot{\mathrm{V}}_{\mathrm{E}}$ was slowly reduced (Fig. 7). It may be that the rate of rewarming was slow enough throughout the course of the experiment to forestall such an effect.

Further support for the pathophysiologic sequence that we are describing can also be found in the literature. Lilker et al. were able to prevent EIA by slowly reducing the work load on a cycle ergometer over a 10-min period (21). Since this maneuver also reduced $\dot{\mathrm{V}}_{E}$, their findings are analogous to ours. However, because the type of challenge they used could have resulted in an increase in norepinephrine (22-25), which could have limited the obstruction (22), their results could have derived from this source as well as from controlling the rate of rewarming. By using voluntary hyperventilation as the provocative stimulus in 




Figure 5. Effect of breathing air at various temperatures and humidity on $\dot{\mathrm{V}}_{\mathrm{E}}$ (in liters per minute) after a period of exercise on a cycle ergometer. The data points are mean values and the brackets are $1 \mathrm{SE}$. Cold air was inhaled during the exercise period (Ex).

the second part of the current study, we were able to avoid the catecholamine effects $(22,25)$ and so isolate $\dot{\mathrm{V}}_{\mathrm{E}}$ as the critical variable.

The manner in which airway rewarming produces obstruction is unknown. It has been suggested that mediators of immediate hypersensitivity play an important part in the pathogenesis of EIA, and that they can be released either through direct thermal stimulation of mast cells or indirectly through lowering or increasing the tonicity of the airway surface fluid
$(8,9)$. While our results can not confirm or refute that mediators are involved, they do suggest that both airway cooling and rewarming are necessary for the expression of their effects. If either phase is prevented or reduced, obstruction either does not develop or is attenuated (8) (Figs. 2 and 6).

The augmentation of the response by inhaling body condition air in the postchallenge period is difficult to explain solely on the basis of mediator release. It may be that the abrupt change in intraairway temperature and vapor pressure produced by this

Table III. Individual Data Control of $\dot{V}_{E}$ Studies

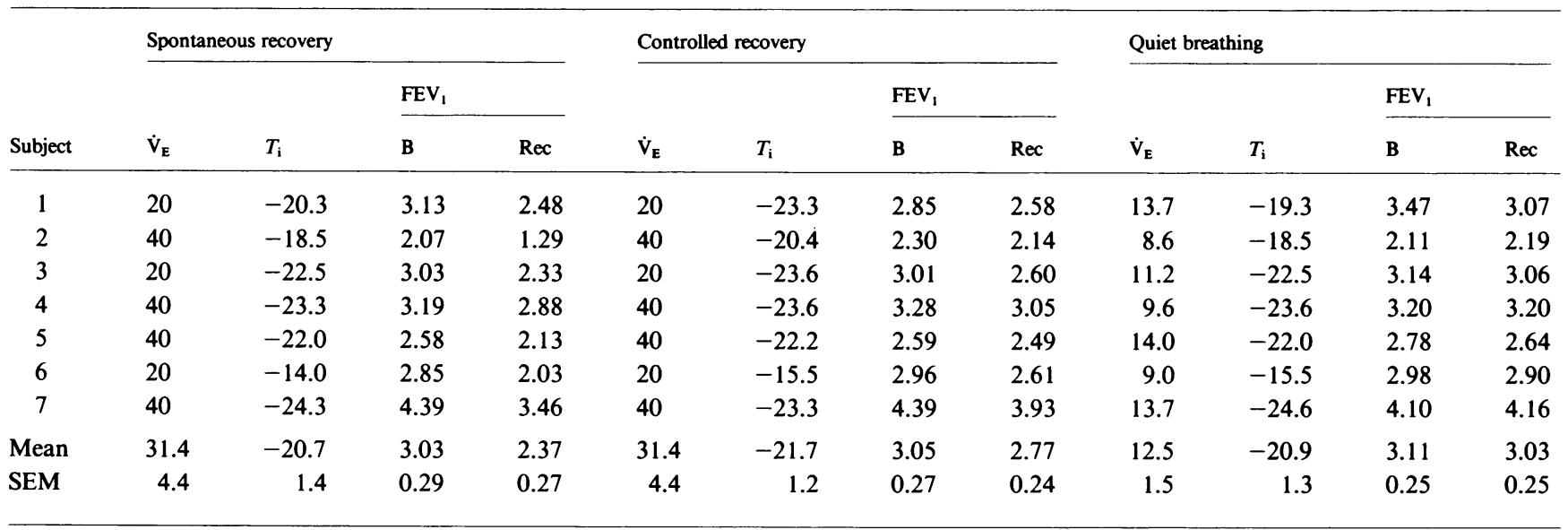

$\dot{\mathrm{V}}_{\mathrm{E}}=$ minute ventilation in liters per minute; $T_{\mathrm{i}}=$ temperature of the inspired air in ${ }^{\circ} \mathrm{C} ; \mathrm{FEV}, 1 \mathrm{~s}$ forced expiratory volume in liters;

$\mathrm{B}=$ baseline; $\operatorname{Rec}=$ data obtained $5 \mathrm{~min}$ after coming off the heat exchanger. 

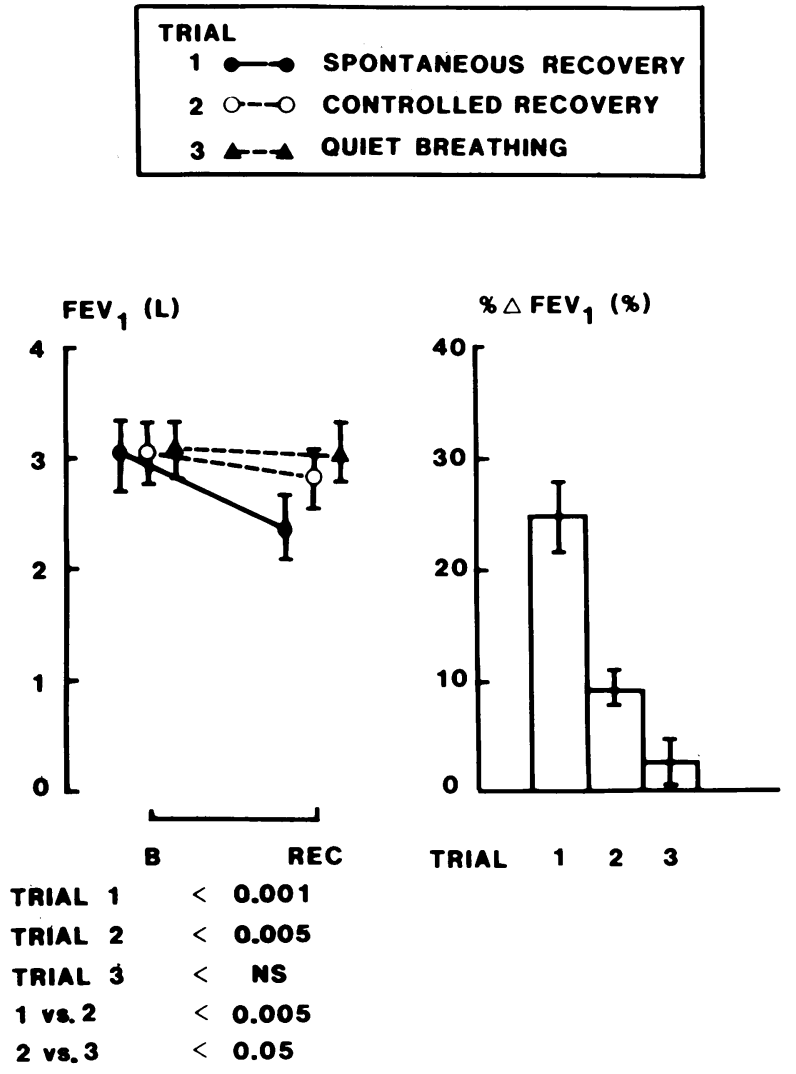

Figure 6. Absolute and relative changes in pulmonary mechanics following isocapnic hyperventilation of frigid air when ventilation is allowed to fall normally in the posthyperpnea period (spontaneous recovery), when it is slowly reduced (controlled recovery), and when the subjects are breathing quietly. The data points and the heights of the bars represent mean values and the brackets are $1 . S E M$. Rec $=$ recovery data 5 minutes after the subjects discontinue breathing on the heat exchanger. The numbers below the left-hand graph show the probability values for baseline recovery comparisons among and between trials.

experiment caused rapid cooling of the airstream with condensation of the excess water onto the airway mucosa. This conceivably could have been an irritant, or it could have changed the tonicity of the surface fluid and through this mechanism caused the liberation of more biologically active substances. We think these possibilities unlikely for several reasons. First, none of the subjects complained of any irritation or had cough. Further, maximum condensation would have tended to occur at the points where the greatest thermal gradients existed, and this would have been in the mouth piece, mouth, and pharynx and much less so in the lower airways $(2,3)$. Second, since normal subjects responded to this manipulation, it would mean that mediators were released in this group, and thus far, none have been found even when specifically sought (26). Third, and most importantly, if changes in tonicity of the surface fluid were producing the effects we observed, we would have expected the greatest response to have occurred in the experiment during which the subjects inhaled cold air for the longest time (controlled recovery, Figs. 6 and 7). According to current theory, these experiments would have produced the greatest water losses and the greatest stimulus for airway drying (9). Yet, they resulted in the smallest degree of obstruction. Therefore, if fluctuations in

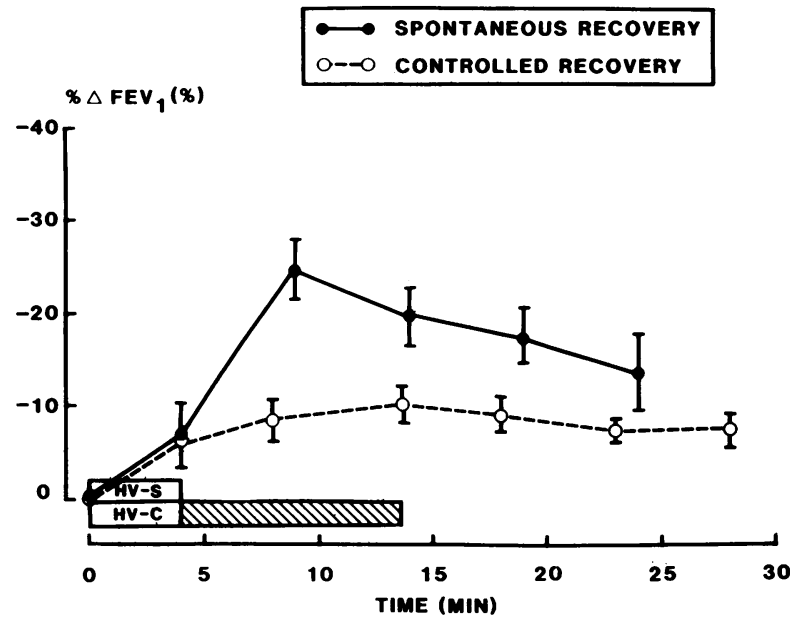

Figure 7. Time course of response in the spontaneous and controlled recovery experiments. The data points are mean values and the brackets represent $1 \mathrm{SE}$. The two clear rectangles represent the period of time spent hyperventilating at the level of $\dot{V}_{E}$ known to reduce $F E V_{1}$ $20 \%$ from control. HV-S and HV-C $=$ spontaneous and controlled $\dot{\mathrm{V}}_{\mathrm{E}}$ experiments, respectively. The cross-hatched rectangle indicates the average additional time that the subjects spent on the heat exchanger while $\dot{\mathrm{V}}_{E}$ was being reduced. The last four data points in the experiment are plotted relative to the average time when the subjects discontinued breathing on the exchanger.

osmolarity are important in explaining our results, one would have to argue that a tendency to increase tonicity protected our subjects' airways while a tendency to maintain normal tonicity worsened them.

One mechanism that could be operative is the possibility that at least part of the obstruction in EIA results from thermally induced changes in the contractility of the smooth muscle in the airways or bronchial vessels or both. In vitro studies on the effects of thermal stimuli on the airway smooth muscle of guinea pig trachea and bronchi reveal extreme sensitivity to sudden changes in temperature (27). In this species, when cooling of the trachealis muscle is followed by rapid rewarming large sustained contractions develop. Slow rewarming does not produce this effect. It is not yet known if the airway smooth muscle in humans responds in a similar fashion, but obviously if it did, such effects could be quite important in the pathogenesis of EIA. Alternatively, if the combination of the cooling of hyperpnea and the abrupt rewarming that occurs with its cessation were to affect the smooth muscle of the bronchial vessels as it does that in the vessels of the skin $(28,29)$, a reactive hyperemia could develop. This in turn could result in luminal narrowing from vascular engorgement and edema in the mucosa and submucosa. The latter phenomenon could be augmented by the local release of mediators since many of the agents that evoke bronchoconstriction also have profound effects on vascular integrity and fluid movement from the capillary lumen into the airway wall. It remains to be determined which, if either, of these postulates is correct.

\section{Acknowledgments}

The authors gratefully acknowledge the generosity and support of Dr. E. C. Deal and Dr. Pamela Davis in providing some of the equipment used in the performance of this study. 
This work was supported in part by grants HL33791 and HL34424 from the National Heart, Lung and Blood Institute, Bethesda, MD. Dr. Strohl holds a Clinical Investigator Award (HL 01067).

\section{References}

1. McFadden, E. R., Jr., D. M. Denison, J. R. Waller, B. Assoufi, A. Peacock, and T. Sopwith. 1982. Direct recordings of the temperatures in the tracheobronchial tree in normal man. J. Clin. Invest. 69:700-705.

2. McFadden, E. R., Jr., B. M. Pichurko, K. F. Bowman, E. Ingenito, S. Burnes, N. Dowling, and J. Solway. 1985. Thermal mapping of the airways in man. J. Appl. Physiol. (Respir. Environ. Exercise Physiol.). 58:564-570.

3. McFadden, E. R., Jr., and B. M. Pichurko. 1985. Intra-airway thermal profiles during exercise and hyperventilation in normal man. $J$. Clin. Invest. 76:1007-1010.

4. Strauss, R. H., E. R. McFadden, Jr., R. H. Ingram, Jr., E. C. Deal, Jr., and J. J. Jaeger. 1978. Influence of heat and humidity on the airway obstruction induced by exercise in asthma. J. Clin. Invest. 61:443-440.

5. Deal, E. C., Jr., E. R. McFadden, Jr., R. H. Ingram, Jr., R. H. Strauss, and J. J. Jaeger. 1979. Role of respiratory heat exchange in the production of exercise induced asthma. J. Appl. Physiol. (Respir. Environ. Exercise Physiol.). 46:467-475.

6. Deal, E. C., Jr., E. R. McFadden, Jr., R. H. Ingram, Jr., and J. J. Jaeger. 1979. Hyperpnea and heat flux: initial reaction sequence in exercise induced asthma. J. Appl. Physiol. (Respir. Environ. Exercise Physiol.). 46:476-483.

7. O'Cain, C. F., N. B. Dowling, A. S. Slutsky, M. J. Hensley, K. P. Strohl, E. R. McFadden, Jr., and R. H. Ingram, Jr. 1980. Airway effects of respiratory heat loss in normal subjects. J. Appl. Physiol. (Respir. Environ. Exercise Physiol.). 49:875-880.

8. Lee, T. H., B. K. Assoufi, and A. B. Kay. 1983. The link between exercise, respiratory heat exchange, and the mast cell in bronchial asthma. Lancet. i:520-522.

9. Anderson, S. D. 1984. Is there a unifying hypothesis for exerciseinduced asthma? J. Allergy Clin. Immunol. 73:660-665.

10. Bleeker, E. R., K. S. Chahal, P. Mason, and S. Permutt. 1983. The effect of alpha adrenergic blockade on non-specific airways reactivity and exercise-induced asthma. Eur. J. Respir. Dis. 64(Suppl. 128):258264.

11. Shepard, R. J. 1977. Exercise-induced bronchospasm-a review. Med. Sci. Sports. 9:1-10.

12. Strauss, R. H., E. R. McFadden, Jr., R. H. Ingram, Jr., and J. J. Jaeger. 1977. Enhancement of exercise-induced asthma by cold air. $N$. Engl. J. Med. 297:743-747.

13. Weast, R. C. (editor). 1978. Handbook of Chemistry and Physics, 58th edition. CRC Press, Cleveland. E41, E45.

14. Deal, E. C., Jr., E. R. McFadden, Jr., R. H. Ingram, Jr., F. J. Breslin, and J. J. Jaeger. 1980. Airway responsiveness to cold air and hyperpnea in normal subjects and in those with hay fever and asthma. Am. Rev. Respir. Dis. 121:621-628.

15. Deal, E. C., Jr., E. R. McFadden, Jr., R. H. Ingram, Jr., and J. J. Jaeger. 1979. Esophageal temperature during exercise in asthmatic and non-asthmatic subjects. J. Appl. Physiol. (Respir. Environ. Exercise Physiol.). 46:484-490.

16. McLaughlin, F. J., and A. J. Dozor. 1983. Cold air inhalation challenges in the diagnosis of asthma in children. Pediatrics. 72:503509.

17. Bundgaard, A., T. Ingemann-Hansen, A. Schmidt, J. HalkjaerKristensen, and I. Bloch. 1982. Influence of temperature and humidity of inhaled gas on exercise-induced asthma. Eur. J. Respir. Dis. 63:239244.

18. Bar-Or, O., I. Newman, and R. Dotan. 1977. Effects of dry and humid climates on exercise-induced asthma in children and pre-adolescents. J. Allergy Clin. Immunol. 60:163-168.

19. Chen, W. Y., and D. J. Horton. 1977. Heat and water loss from the airways and exercise-induced asthma. Respiration. 34:305-313.

20. Anderson, S. D., E. Daviskas, R. E. Schoeffel, and S. F. Unger. 1979. Prevention of severe exercise-induced asthma with hot humid air. Lancet. ii:629.

21. Lilker, E. S., M. Manisatide, W. O'Hara, and K. Lasachuk. 1985. Exercise induced asthma is prevented by warm down. Am. Rev. Respir. Dis. 131:A48. (Abstr.)

22. Pichurko, B. M., B. Sullivan, R. J. Porcelli, and E. R. McFadden, Jr. 1986. Endogenous adrenergic modification of exercise-induced asthma. J. Allergy Clin. Immunol. 77:796-801.

23. Hartley, L. H., J. W. Mason, R. P. Hogan, L. G. Jones, T. A. Koto, E. H. Mougey, F. E. Wherry, L. L. Pennington, and P. T. Ricketts. 1972. Multiple hormonal response to graded exercise in relation to physical training. J. Appl. Physiol. 33:602-606.

24. Watson, R. D. S., C. A. Hamilton, D. H. Jones, J. L. Reid, J. J. Stallard, and W. A. Littler. 1980. Sequential changes in plasma noradrenaline during bicycle exercise. Clin. Sci. 58:37-43.

25. Barnes, P. J., M. J. Brown, M. Silverman, and C. T. Dollery. 1981. Circulating catecholamines in exercise and hyperventilation induced asthma. Thorax. 36:435-440.

26. Lee, T. H., M. J. Brown, L. Nagy, R. Causon, M. J. Walport, and A. B. Kay. 1982. Exercise-induced release of histamine and neutrophil chemotactic factor in atopic asthmatics. J. Allergy Clin. Immunol. 70: $73-81$.

27. Souhrada, J. F., D. Presley, and M. Souhrada. 1983. Mechanisms of the temperature effect on airway smooth muscle. Respir. Physiol. 53: 225-237.

28. Savard, G. K., D. E. Cooper, W. L. Veale, and T. J. Malkinson. 1985. Peripheral blood flow during rewarming from mild hypothermia in humans. J. Appl. Physiol. 58:4-13.

29. Thauer, R. 1965. Circulatory adjustments to climatic requirements. In Handbook of Physiology. Circulation. W. F. Hamilton and P. Dow, editors. Waverly Press, Baltimore. 3:1921-1966.

30. Wasserman, S. I. 1983. Mediators of immediate hypersensitivity. J. Allergy Clin. Immunol. 72:101-105. 